\section{Neutral vs ego-orienting instructions: Effects on judgments of magnitude estimation*}

\author{
JEFFREY GOLDNER,** MARY E. REUDER, BENJAMIN RIBA,, \\ and DAVID JARMON†† \\ Queens College of the City University of New York, Flushing, New York 11367
}

Three experiments were performed to examine the relative constancy of the exponent in the psychophysical power law under varying motivating conditions. The method of magnitude estimation was used to obtain judgments of apparent tactual roughness or of apparent area size of squares. Patterns of the qualitative observations of the three Es and of the various exponents for the six groups of Ss indicated that neutral instructions and "ego-orienting" instructions, which were perceived as unbelievable coming from an equal fellow student, both yielded exponents identical to those reported in the literature. Believable ego-orienting instructions given by an $\mathbf{E}$ of clearly perceived higher social status produced a statistically significantly lower exponent than neutral. Intermediate conditions, wherein Ss apparently disbelieved both types of instructions, but assumed that the superior-status E was "analyzing" them, yielded exponents of intermediate size. Results and supplementary trend analyses are discussed as possible, highly sensitive indicators of motivational impacts on sensory judgments.

The majority of studies of psychophysical judgments using the method of magnitude estimation have been directed toward demonstrating that the psychophysical power law holds for a wide variety of prothetic phenomena across many sensory modalities (see references in Ekman, 1961; Ekman, Hosman, \& Lindström, 1965; Stevens, 1962).

Operationally, the power law $\left(\psi=k \phi^{n}\right)$ states that a log-log plot of the geometric means of $\mathrm{Ss}^{\prime}$ responses will produce a rectilinear distribution with a slope equal to $\mathrm{n}$.

Although no explicit claim appears to have been made expressly for constancy of exponent for a modality, the repeated publication of precise lists of values (e.g. Stevens, 1961) contains such an implication (Ekman, 1961). At least relative constancy is further implied by the use of identity of exponent as the major criterion in cross-modality stimulus-matching techniques (Stevens, 1962).

Recent findings, however, suggest that the value of the exponent may also be relative to the particular conditions under which the judgments are made. Thus,

\footnotetext{
*The portion of this paper based upon Experiment I was reported at the 36th Annual Meeting of the Eastern Psycho' ' roical Association Atlantic City, N.J., April 1965. The first author received the President's Award for "The most outstanding research paper at the meeting in which the principal investigator was an undergraduate student."

**Now with the Lamont Geological Observatory, Palisades, N.Y.

fNow at North Rockland Central School District, Haverstraw, N.Y.

$\dagger$ Now at Southern Illinois University.
}

exponent differences may prove to be a highly sensitive index to effects of modifications of experimental procedures. Jones and Marcus (1961) and Ekman, Hosman, and Lindström (1965) have reported intra-S differences within the same modality. Stevens and Stevens (1963) found changes with variations in brightness adaptation of the eye. And Pradhan and Hoffman (1963) reported changes in exponent with changes in range of stimuli. Teghtsoonian (1965) modified the instructions given to her Ss and found that instructions to report area of circles resulted in a different exponent from instructions to report apparent size of the circles.

Neither a further search of the literature nor the observations of any of the aforementioned writers yielded reports of experimental findings related to motivational variables-at least with respect to this aspect of psychophysics. However, in a different context, Swets's (1963) literature review pinpointed the impact of a wide range of cognitive factors (including motivational) on auditory frequency selectivity thresholds. tremendous literature showing the effects of ego orientation and stress on a wide variety of learning, problem-solving, and perceptual tasks (e.g., Iverson \& Reuder, 1956; Cofer \& Appley, 1964). A common finding has been that ego-orienting conditions (including instructions and social-status differences) alter the functional relationships obtained under neutral conditions.

Three separate experiments were therefore undertaken in which the major objective was to compare curves obtained
Outside of psychophysics there is a under ego-orienting instructions with those obtained using the "neutral" instructions reported by Stevens and his associates.

\section{THE EXPERIMENTS}

Each of the three experiments employed the same general experimental design with instructions as one major independent variable. All used the method of magnitude estimation as described in Stevens and Harris (1962) to obtain sensory judgments. Each experiment differed in the total number of stimuli employed. In addition, Experiments I and III required Ss to judge the apparent tactual roughness of sandpaper grits, whereas Experiment II was concerned with judgments of apparent size of squares.

Because the impact of ego-orienting instructions can be seriously altered by S's perception of the social status of $E$ with respect to himself (Iverson, 1962), certain unavoidable qualitative differences between experiments on this factor should be noted.

In Experiment I, Ss were 20 high school boys. $E$ was about five years older than they were. He held a position of superior status, with respect to the students in the school, and was known to them to be "studying psychology in college." In Experiment II, Ss were 24 college students recruited by $E$. A substantial number (but not all) Ss were acquainted with $E$ prior to the experiment. Their commentaries indicated that they tended to view him as a peer and fellow student. Many were either psychology majors or had had several courses in the subject. Experiment III employed $40 \mathrm{Ss}$, all of whom were volunteers from evening Psychology 1 courses (a prerequisite to all other psychology courses). All were strangers to $\mathrm{E}$, who was a recent graduate of the college and a laboratory assistant in experimental psychology, although in age similar to many Ss (evening students being much more variable in age).

\section{Common Design}

Although it is not customary to apply inferential statistics to psychophysical data, they appeared to be especially useful for these studies. A p by $q$ by ... by $r$ (repeated measures) design provided a statistical test of differences in response of the same Ss to the different stimuli. At the same time the Instructions by Stimulus interactions would clearly determine if small differences in slope between groups were likely to be chance outcomes. The latter factor was especially important because the nature of the instructions variable precluded using $S s$ as their own controls-a methodology commonly employed in Stevens's studies. 


\section{Experiment I}

Procedures. The independent variables were instructions (ego-orienting and neutral) and hand dominance. There were thus four groups of five Ss each.

The work of Semmes, Weinstein, Ghent, and Teuber (1960) and of Weinstein and Serson (1961) had shown that sensitivity to roughness was related to sensitivity to punctate pressure. It had also shown that sensitivity to punctate pressure was related to hand dominance. Therefore, although all Ss were right-handed, one half made their judgments with the dominant hand and one half with the nondominant.

Likewise, as noted previously, one-half of the Ss were given neutral instructions identical to those of Stevens and Harris. The other half were given the same instructions with the additional statement (carefully emphasized by voice inflection) that the results would be used as a "measure of your aesthetic sensitivity and creative ability."

The stimuli consisted of seven Tri-M-Ite brand sandpaper grits (ranging from No. 400 to No. 36). Number 120 was chosen as modulus and assigned the value of 10. It was not further included among the variable stimuli.

In accordance with the method of magnitude estimation, the $20 \mathrm{Ss}$ were first presented with the standard and told that it had a value of 10 . They were then required to assign a number of their choice (relative to the standard) to the six other randomly presented stimuli. Each stimulus was judged twice in terms of how rough it felt, in accord with Stevens's procedure (Stevens \& Harris, 1962; Stevens, 1961).

Results. Stevens's method of treating data is to pool all responses of all $S$ s to the same stimulus, determine each geometric mean, and place all such means on a log-log plot against stimulus value. This method does not provide any measures of error variability for making further statistical tests. A minor procedural adaptation, however, produced the identical curve and also measures of variability. A separate distribution was prepared for each stimulus value. For each value the $\log$ geometric mean was determined for each $S$. The arithmetic mean of this distribution yields the same value as Stevens's method and between-S variability permits obtaining estimates of sampling error. The means and standard deviations of Ss receiving ego-orienting and neutral instructions can be found in Table 1.

The analyses of variance showed highly significant main effects for the stimulus variable $(F=214.99, \mathrm{df}=5 / 80, \mathrm{p}<.001)$. It was thus obvious that $S$ s were differentiating among the stimuli. The Instructions by Stimulus interaction was
Table 1

Means and Standard Deviations of Distributions of Log Geometric Means of Roughness Judgments for Each Stimulus Value for Each Instructions Group in Experiment I( $\mathbf{N}=10$ per Group) and Experiment III ( $N=20$ per Group)

\begin{tabular}{|c|c|c|c|c|c|c|c|c|c|c|}
\hline & & \multicolumn{9}{|c|}{ Sandpaper Grit Number (Tri-M-Ite or 3M) } \\
\hline & & 36 & 40 & 50 & 60 & 80 & 120 & 220 & 320 & 400 \\
\hline \multicolumn{11}{|c|}{ Experiment I } \\
\hline \multicolumn{11}{|c|}{ Ego-Orienting Instructions: } \\
\hline & Mean & 1.427 & - & 1.374 & - & 1.233 & - & .918 & .640 & .397 \\
\hline & $\mathrm{SD}$ & .151 & - & .156 & - & .093 & - & .132 & .185 & .162 \\
\hline \multicolumn{11}{|l|}{ Neutral Instructions: } \\
\hline & Mean & 1.571 & - & 1.470 & -- & 1.308 & - & .859 & .549 & .366 \\
\hline & SD & .179 & - & .130 & - & .058 & - & .085 & .204 & .187 \\
\hline \multicolumn{11}{|c|}{ Experiment III } \\
\hline \multicolumn{11}{|c|}{ Ego-Orienting Instructions: } \\
\hline & Mean & -- & 1.483 & -- & 1.238 & L.192 & .700 & .626 & .477 & .348 \\
\hline & SD & -- & .164 & -- & .147 & .140 & .326 & .303 & .307 & .234 \\
\hline \multicolumn{11}{|l|}{ Neutral Instructions: } \\
\hline & Mean & -- & 1.469 & - & 1.284 & 1.245 & .763 & .537 & .414 & .312 \\
\hline & SD & - & .173 & - & .182 & .184 & .230 & .235 & .297 & .253 \\
\hline
\end{tabular}

also statistically significant $(\mathrm{F}=2.57$, $\mathrm{df}=5 / 80, \mathrm{p}<.05$ ). Thus, the slope (or exponent) for the ego-instructed group differed from that of the group that received neutral instructions.

The two curves were superimposed on a As can be seen in Fig. 1, the curve for the neutral group was completely parallel to that of Stevens and Harris and had the identical slope (1.4). Thus, the findings reported by them for samples from other populations can be generalized to the present sample of high school boys.

The curve for the ego-oriented group had a less steep slope (1.06). These Ss judged the extreme values to be more photograph of the Stevens and Harris data. rough (or less rough) than did the neutral group. This result conformed with a general finding (Iverson \& Reuder, 1956) that ego-orienting conditions tend to make Ss more variable in response than do neutral conditions. It also corresponded to Stevens's observation that "anything which makes the Ss more variable will reduce the size of the exponent [private communication]." This inference must be qualified, however. At least for Experiment $\mathbf{I}$, the standard deviations for the ego group were not noticeably different from those of the neutral Ss. Yet in Experiment III, the SDs, as expected, were substantially larger.

An absence of any clearcut differences

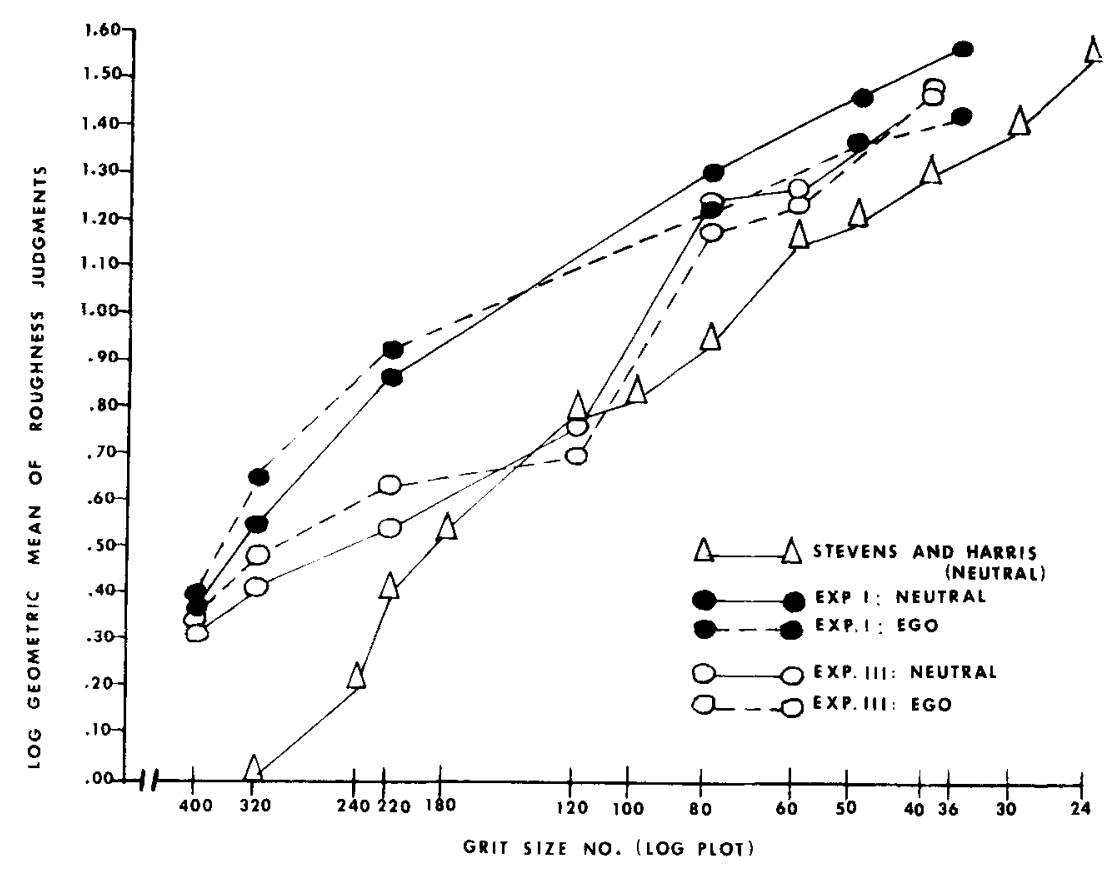

Fig. 1. Exact plot of $\log$ of geometric means of judgments of tactual roughness by $\log$ of stimulus grit values comparing Experiments I, III, and Stevens and Harris (1962). 
Table 2

Means and Standard Deviations of Distributions of Log Geometric Means of Apparent Size Judgenent for Each Stimulus Value for Each Instructions Group in Experiment II ( $N=12$ per Group)

\begin{tabular}{|c|c|c|c|c|c|c|c|c|c|c|}
\hline & & \multicolumn{9}{|c|}{ Area of Square Stimulus (Square Inches) } \\
\hline & & 1 & 4 & 9 & 16 & 25 & 36 & 49 & 64 & 81 \\
\hline \multicolumn{11}{|c|}{ Ego-Orienting Instructions: } \\
\hline & Mean & 1.010 & 1.052 & 1.070 & 1.086 & 1.098 & 1.111 & 1.120 & 1.125 & 1.133 \\
\hline & $\mathrm{SD}$ & .019 & .010 & .005 & .005 & .005 & .007 & .042 & .008 & .010 \\
\hline \multicolumn{11}{|l|}{ Neutral Instructions: } \\
\hline & Mean & 1.017 & 1.057 & 1.072 & 1.090 & 1.100 & 1.114 & 1.121 & 1.128 & 1.136 \\
\hline & SD & .021 & .013 & .008 & .008 & .010 & .004 & .005 & .008 & .008 \\
\hline
\end{tabular}

with respect to hand dominance (either in magnitude of judgments or slope) was puzzling in view of the work of Weinstein and Serson (1961). The facts that there was a slight trend $(p \approx .10)$ for larger judgments with the nondominant hand, that our Ss were all right-handed, that $\mathbf{N}$ was only 10 per group, and that Weinstein and Serson used $S s$ as their own controls-all indicated factors to be studied further before any conclusions can be drawn.

Qualitative observations, ${ }^{1}$ although highly subjective, also tended to verify differences between the two instructions groups. The neutral group was quiet, cooperative, and unquestioning. They showed little or no restlessness or concern. In contrast, E's notes indicated that individuals in the ego-oriented group were extremely restless. They appeared agitated and emitted much nervous laughter and movement. Whereas neutral Ss merely gave a judgment (e.g., "35"), ego-oriented Ss phrased judgments in the form of a question (e.g., "Is it 20?"). They also constantly made such inquiry as, "Am I doing all right?"

\section{Experiment II}

Purpose. Experiment II was undertaken primarily to explore further the findings of Experiment I by using a wider range of stimulus values ( 9 vs 6 ), more Ss (24 vs 20), more judgments by $S$ per stimulus (3 vs 2), and a sample from a different population (college vs high school students). It was also hoped that a different stimulus variable might provide findings that could be generalized beyond the judgments of roughness found in Experiment I.

Procedure. A 2 by 2 by 9 mixed design, basically similar to that used in Experiment I was employed. The major difference was that $\mathrm{S}$ s were asked to judge the apparent size of the area of black squares painted on a uniform white background.

The independent variables were: instructions (ego-oriented and neutral), distance of stimulus from the $\mathrm{O}(3$ and $10 \mathrm{ft}$ ), and size of plane squares.
Except for slight modifications necessary for differences in task, the two types of instructions were the same as in Experiment I. Stimuli were squares with areas of $1,4,9,16,25,36,49,64$, and $81 \mathrm{sq}$ in. The 25 -in. square was chosen as modulus and assigned a value of 10 . It was later included in the random presentation of the variable stimuli.

The procedure was run in a laboratory corridor with which some, but not all, Ss were familiar. Using the method of magnitude estimation, all of the Ss who were assigned to each combination of experimental conditions judged all of the randomly presented stimuli.

Results. Data were treated in exactly the same way as those in Experiment I. The analyses of variance of the logs of the geometric means reaffirmed Ss' ability to differentiate stimuli using Stevens's method. The Fratio was 408.67 ( $\mathrm{df}=8 / 160)$, which was significant far beyond the .001 level of confidence. There were no significant interactions between either instructions and stimulus or distance

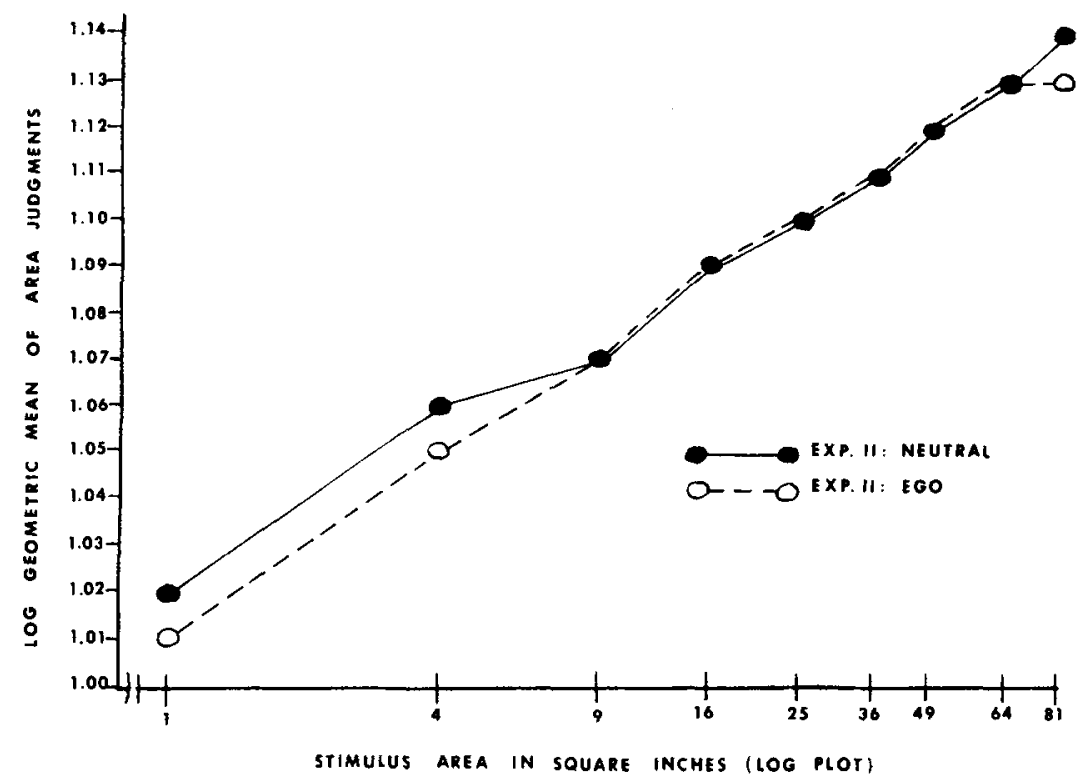

Fig. 2. Exact plot of $\log$ of geometric means of judgments of area size by $\log$ of stimulus area for Experiment II. and stimulus-indicating that the slope (or exponent) was about the same for all groups.

Because this study was performed primarily for purposes of comparison with Experiment I, the data for the ego-instructed and neutral groups were examined separately. The means and standard deviations (Table 2) were practically identical. Interestingly enough, not only were the two slopes (.69 and .71) practically the same (see Fig. 2), they were also essentially the same as the slope of .70 reported by Stevens and Guirao (1963) for similar judgments under neutral instructions.

The small (and nonsignificant) impact of the distance variable merely confirmed the well-known conclusion from studies of size constancy - that for distance to have much effect on $O$ judgments, it must be greater than $10 \mathrm{ft}$. In designing this experiment, the investigators were primarily concerned about possible interactions of the distance and instructional variables. The failure of the latter variable to function as intended precluded further examination of this possibility.

Qualitative observations of the two instructions groups in this experiment tended to support the quantitative findings-in this case, an outcome of "no difference" in slope between the groups. Furthermore, the overall behavior of both groups could be most aptly characterized as most like that of the neutral group in Experiment I (and their slopes were like that found by Stevens and Guirao using neutral instructions-see Table 3). 
Table 3

Slopes of Curves for Two Types of Instructions Groups in Experiments I, II, and III and Those Reported in Related Studies

\begin{tabular}{llccc}
\hline \multirow{2}{*}{$\begin{array}{c}\text { Type of } \\
\text { Judgments }\end{array}$} & \multicolumn{1}{c}{ Study } & \multicolumn{2}{c}{ Instructions Type } \\
\cline { 2 - 5 } Apparent & Experiment I & N/Group & Neutral & Ego \\
Tactual & Experiment III & 10 & 1.40 & 1.06 \\
Roughness & Stevens \& Harris (1962) & 20 & 1.18 & 1.17 \\
Apparent & Experiment II & 20 & 1.40 & - \\
Size of Square Area & Stevens \& Guiaro (1963) & 12 & .71 & .69 \\
\hline
\end{tabular}

Careful examination of E's notes suggested that at least two factors (possibly interacting with each other) were probably responsible. Both the plausibility of the ego-orienting instructions and E's status as a fellow student of $\mathrm{S}$ (who in many cases was a psychology major or a fraternity brother) appeared to be relevant.

The neutral group appeared to take the task seriously. However, their comments suggested that they were doing so largely to help a fellow student meet a course requirement. There was little expressed concern for what performance on the task might "reveal" with respect to themselves.

The ego-oriented group's comments reflected open disbelief of the instructions (e.g., "You don't really expect me to believe that, do you?" or "Are you kidding?'). There were few, if any, overt indications of concern about quality of performance. Postexperimental interview further indicated disbelief that the task could possibly be an index of anything-much less aesthetic judgment! Several sophisticated Ss also noted that if it really did measure such judgment, college ethics would not permit an undergraduate student to use it on his fellows.

\section{Experiment III}

Purpose. This experiment was undertaken to clarify certain aspects of the previous two studies. As in Experiment I, the dependent measure was judgments of tactual roughness (three per stimulus instead of two). The same instructions were employed, but with one more stimulus ( 7 vs 6). There were also more Ss (40 vs 20). Different populations were sampled (college vs high school students). However, unlike those in Experiment II, all Ss were volunteers from the general psychology evening classes. Although averaging about the same age as $\mathrm{E}$, all were strangers to him. With respect to the Ss, E had the status of being the graduate assistants in the evening courses in experimental psychology. All instructors in the evening division tended to emphasize the learning value of actual research participation, and most enrolled students were on the volunteer list. Thus some of the extraneous factors involved in
Experiment II were at least partially controlled.

Procedure. In addition to the tactual-roughness judgments and the instructions variable, two new independent variables (sex and the personality measure called locus of control) were employed. Thus the $40 \mathrm{Ss}$ were assigned five to a group in a 2 by 2 by 2 by 7 mixed design.

A study in our laboratory (utilizing a different psychophysical method) had shown that differences on this personality variable were related to accuracy of perceived brightness matches (Alexander, 1968). It was because studies of locus of control (Rotter, 1966; Lefcourt, 1966) had shown inconsistent relationships between this variable, sex, and various dependent measures that sex was treated as a separate variable in Experiment III.

The sandpaper stimuli used consisted of seven $3 \mathrm{M}$ (Minnesota Mining \& Manufacturing) brand grits, ranging from No. 400 to No, 40. (The manufacturer of the Tri-M-Ite grits used in Experiment I has stopped producing most of them.)

Half of the men and half of the women were given the locus-of-control scale followed by the judgments of tactual rulughness. The other half was given the scale last. Half of each of these groups received, the neutral instructions and half the ego-orienting.

Results. The analysis of variance of the logs of the geometric means of $\mathrm{Ss}^{\prime}$ judgments again showed a highly significant main effect for stimulus differences $(F=205.35, \quad d f=6 / 192$, $p<.001)$. Thus, despite the difference in brand of grits, the results provided further confirmation of Stevens and Harris's results.

As in Experiment II, none of the interactions of instructions, sex, or locus of control with the stimulus variable reached a level of statistical significance. Because the sex and locus-of-control variables were included primarily to shed light on the findings of a different study, they are not considered further herein.

Again for comparison purposes, the data for the 20 ego-oriented and 20 neutral Ss were separated and examined individually. Their means and standard deviations can be found in Table 1. It can be readily noted that although the means in Experiments I and III were similar, the SDs in Experiment III were generally larger. Furthermore, the SDs of the ego-oriented group were consistently larger than those of the neutral group.

Examination of the actual slopes (Fig. 1 and Table 3 ) of the two curves confirmed the analyses of variance. The slopes were practically identical. The ego group had a slope of 1.17 and the neutral group one of 1.18. These values were intermediate between the two obtained for similar instructions differences in Experiment $I$. This suggested the possibility that both groups in Experiment III may have been responding in an ego-threatened manner to the experimental situation-or at least more so than the two groups in Experiment II.

The qualitative notes contained observations that partially supported this suggestion. E's written observations showed little difference in his behavior descriptions of the ego- and neutral-instructed groups. However, the majority of descriptions of Ss in both of these groups were quite different from those in Experiments I and II.

The majority of the $40 \mathrm{Ss}$ in Experiment III were described as "wary," "partially disbelieving," or "suspicious." They tended collectively to be somewhat restless (but not as much so as the ego Ss in Experiment I). Postexperimental interviews indicated that very few of the ego-oriented Ss accepted at face value the instructions that the task was a measure of "aesthetic sensitivity," etc. However, almost all Ss (regardless of instructions) made comments reflecting a belief that $E$ had a concealed motive and was in some way getting at an individualized personal diagnosis of themselves-although they could not articulate further what this might be. As one $S$ put it, "It's not aesthetics, but you're psyching me some way." A few Ss in both groups behaved like those in Experiment II and scoffed at the whole procedure or took it as a routine task of judgment with few if any personal overtones.

\section{DISCUSSION}

First and foremost, it should be noted that the application of inferential statistics in the mixed analyses of variance provided incontrovertible support of Stevens's major contention. Analyses of all six curves showed that Ss differentiated clearly among the stimuli presented by the method of magnitude estimation. All F-ratios were statistically significant far beyond the .001 level of confidence.

A second finding, although much more 
tentative, was supported by overlapping agreement of the quantitative and qualitative observations of the three studies taken together with the published findings of other investigators. This observation was that differences in instructional effects were reflected in differences in the obtained slopes or exponents of the curve.

Teghtsoonian (1965) showed that the obtained exponent differed depending upon what $S$ was asked to judge. Her Ss responded quite differently when given instructions to judge actual as opposed to apparent size of circles. Both of her sets of instructions, however, could be said to compare with our "neutral" groups with respect to motivation arousal.

In the present three experiments, all Ss were asked to judge apparent magnitude. Their instructions were varied in that one half were of the traditional neutral type, whereas the other half contained the implication that the quality of S's responses would in some way reflect "how good" he was.

Comparisons of the results of the three experiments (both quantitative and qualitative) indicated that merely modifying the wording of the instructions was in itself not adequate to produce consistent findings. The similarities and differences among populations sampled and the obtained variations in slopes of curves that were consistent with qualitative observations indicated that a highly complex phenomenon was operating.

The overall pattern of the findings suggested the speculation that both the plausibility of the instructions as worded with respect to Ss' sophistication and E's relative social status with respect to $S$ (as the "source" of the instructions) could affect the experimental outcome. In Experiment I, where these factors were both rather clearly disparate, the ego and neutrally instructed groups differed significantly both in magnitude of the slopes of the curves and in qualitative descriptions of behavior. In Experiment II, findings suggested that neither the plausibility of the instructions for $S$ nor E's social status was appropriate for producing ego orientation. Not only was there no difference between the groups, but the magnitudes of the obtained slopes were practically identical to that reported in the literature for neutral conditions. Qualitative descriptions were similar for both instructions groups and were like those for the neutral group in Experiment I.

The magnitude of the slopes, qualitative descriptions, and absence of instructions-groups differences in Experiment III suggested that both of these groups were ego-oriented-but not because of the instructions. The latter appeared to lack plausibility. Rather, the critical factor appeared to be E's superior status with respect to $S$ combined with the fact that $S$ knew he was participating in a Psychology Department research project.

A definitive study clarifying these various elements is obviously needed. ${ }^{2}$ Furthermore, the fact that in Experiment I, the ego-oriented Ss had a slope very close to 1.00 , and the fact that Teghtsoonian found such a slope for Ss judging actual (as opposed to apparent) size, indicates the need to control this element before conclusions can be definitive.

As part of a theoretical consideration, Jones and Marcus (1961) and Pradhan and Hoffman (1963) had independently raised the issue as to whether or not the log-log plots of magnitude estimations against stimulus values was truly rectilinear. Data from our three experiments were in such a form as to lend themselves readily to trend analyses to throw light on this question. Analyses of all six curves showed that at least $91 \%$ of the variance attributable to differences in response to the different stimuli (over and above sampling error) was rectilinear. Thus, pragmatically, the curves were all "basically linear" in accord with Stevens's assertions and the results of hundreds of published studies.

However, at a theoretical level, it was possible that this linearity was characteristic of only part of a curve that actually belonged to a family of curves of a different order. The trend analyses of each of the six curves all suggested such a likelihood. In every case the nonlinear residuals were statistically significant $(p<.001)$. In addition, the patterns differed from one experiment to the next. In some groups the residual was predominantly cubic and in others quartic or quadratic. There was no immediately apparent relationship between these differences and the systematic variations among the three experiments. At the same time, the consistency of these significant departures from linearity cannot be ignored. It is apparent that the problems that confronted Fechner have not completely disappeared. It is also possible that differences in pattern of such residuals may provide an additional indicator that is sensitive to modifications in experimental procedures.

\section{REFERENCES}

ALEXANDER, L. J, Internal-external locus-of-control and knowledge of results in brightness matching. Paper presented at the 39th Annual Meeting, Eastern Psychological Association, Washington, D.C., April 1968.

COFER, C. N., \& APPLEY, M. H. Motiration: Theory and research. New York: Wiley, 1964.

EKMAN, G. Some aspects of psychophysical research. In W. A. Rosenblith (Ed.), Sensory communication. Cambridge, Mass: M.I.T. Press, 1961. Pp. 35-47.

EKMAN, G., HOSMAN, J., \& LINDSTRÖM, B. Roughness, smoothness, and preference: $A$ study of quantitative relations in individual subjects. Journal of Experimental Psychology, $1965,70,18-26$.

IVERSON, M. A. Interpersonal comparability and verbal conditioning. Paper presented at the 70th Annual Meeting, American Psychological Association, St. Louis, Mo.. 1962.

IVERSON, M. A., \& REUDER, M. E. Ego involvement as an experimental variable. Psychological Reports Monograph Supplement, 1956, No. 4, 147-181.

JONES, F. N., \& MARCUS, M. J. The subject effect in judgments of subjective magnitude. Journal of Experimental Psychology, 1961 $61,40-44$.

LEFCOURT, H. Internal and external control of reinforcement. Psychological Bulletin, 1966 65, 206-220.

PRADHAN, P. L., \& HOFFMAN, P. J. Effect of spacing and range of stimuli on magnitude estimation judgments. Journal of Experimental Psychology, 1963, 66, 533-541.

ROTTER, J. B. Generalized expectancies for internal and external control of reinforcement. Psychological Monographs, 1966, 80, No. 1

SEMMES, J., WEINSTEIN, S., GHENT, L., \& TEUBER, H. E. Somato-sensory changes after penetrating brain wounds in man. Cambridge: Harvard University Press, 1960.

STEVENS, J. C., \& STEVENS, S. S. Brigh tness function: Effects of adaptation. Journal of the Optical Society of America, 1963, 53 375-385.

STEVENS, S. S. The psychophysics of sensory function. In W. A. Rosenblith (Ed.), Sensory communication. Cambridge, Mass: M.I.T. Press, 1961. Pp. 1-33.

STEVENS, S. S. The surprising simplicity of sensory metrics. American Psychologist, 1962, 17, 29-39.

STEVENS, S. S., \& GUIRAO, M. Subjective scaling of length and area and the matching of length to loudness and brightness. Journal of Experimental Psychology, 1963, 66, 177-186.

STEVENS, S. S., \& HARRIS, J. R. The scaling of subjective roughness and smoothness. Journal of Experimental Psychology, 1962, 64, 489-494.

SWETS, 3. A. Central factors in auditory frequency selectivity. Psychological Bulletin, $1963,60,429-440$.

TEGHTSOONIAN, M. The judgment of size. American Journal of Psychology, 1965, 78, 392-402.

WEINSTEIN, S., \& SERSON, E. A. Tactual sensitivity as a function of handedness and laterality. Journal of Comparative \& Physiological Psychology, 1961, 54, 665-669.

\section{NOTES}

1. Experiments I, II, and III were each conducted by a different $E$ and in different years. Each E kept running notes on the qualitative behavior of $S$ as well as recording the quantitative judgments. No $\mathrm{E}$ had access to or any knowledge of the contents of the qualitative notes made by the other Es.

2. The results of Experiment IIl led to formulation of tentative plans for such an investigation. However, a change in the code of ethical restrictions for undergraduate research at the authors' institution precluded execution of the study. Personnel and financial resources werc not adequate to permit compliance with the procedures.

(Accepted for publication May 28, 1970.) 